\title{
THE EFFECT OF STRAIN RATE ON POSITION OF FORMING LIMIT CURVE
}

\author{
Vít NOVÁK, Michal VALEŠ, František TATÍČEK, Jan ŠANOVEC, Lukáš CHRÁŠŤANSKÝ \\ CTU - Czech Technical University in Prague, Prague, Czech Republic, EU \\ vit.novak@fs.cvut.cz
}

https://doi.org/10.37904/metal.2019.825

\begin{abstract}
To evaluate formability in sheet metal forming, experimentally determined Forming Limit Curves (FLC) are often used. These conventional curves represent the forming limits of a material. The most widely used approach to experimentally determine the onset of necking of sheet metals is formulated in EN ISO 12004-2. The first goal of this work is to investigate limit strains for dual phase steel HCT490X with nominal thickness $0.6 \mathrm{~mm}$. The second goal is to evaluate influence of strain rate on position of forming limit curve also for material HCT490X. The FLC curve has been measured through Nakajima test on universal testing machine. The test set-up and the shape of samples result from EN ISO 12004-2. Unrepeatable, isotropic and highly contrast pattern was applied on samples and was measured using 3D photogrammetric system ARAMIS by GOM. The punch movement velocity was gradually changed and experimentally measured forming limit curves are compared in this paper.
\end{abstract}

Keywords: Strain rate, sheet metal forming, forming limit curve, nakajima test, dual phase steel

\section{INTRODUCTION}

The basic property of the material in terms of the forming process is limit of plasticity. It is a property that shows the degree of possibility of material deformation without crack initiation. One of the most widely used ways of displaying the material's limit of plasticity is through the forming limit diagram. The forming limit diagram (FLD) was discovered and developed by Keeler and Goodwin, which has been widely applied in analysis of sheet metal forming. The forming limit diagram containing major/minor strain points and shows how much material can be deformed before crack initiation. Forming limit curve, the key feature of the FLD describes the maximum limit of forming sheet metal material and defines transition between a safe area (no necking) and dangerous area (necking and splitting). The zone below the FLC is safe and the zone above is dangerous. The FLC describes the formability in the range from uni-axial to bi-axil deformation. The FLC is affected by many factors, such as the thickness of sheets, the forming speed, the strain hardening, the lubrication condition and the anisotropy of the sheet metals. The most widely used approach to experimentally determine the onset of necking of sheet metals is formulated in EN ISO 12004-2:2008. This standard describes the testing and evaluation procedures for determination of FLC's for metal sheets with thickness between $0.3 \mathrm{~mm}$ and $4 \mathrm{~mm}$ at ambient temperature and using linear strain paths. ARAMIS is a non-contact and material independent optical $3 \mathrm{D}$ measuring system. The system analyses accurate surface strain values, for static or dynamically loaded test objects. The software computes coordinate in 3D space and over time. The software clearly assigns the points from the camera images to each other and compute displacements, strains and derived values such as velocities or accelerations. The algorithm is based on the evaluation of the strain distribution based on the displacement field which is evaluated by optical measurement and treated as a mesh of a finite element calculation. To compute the 3D coordinates, the software needs reference points applied on the part or an applied stochastic pattern (Figures 5, 6). In this article, the FLC curve was measured and constructed by ARAMIS system for each section of the HCT490X+Z100 during the Nakajima test. This research presents strain rate dependent on position of forming limit curve for material HCT490X+Z140. [1-7] 


\section{MATERIAL AND EXPERIMENTAL PROCEDURE}

The essential aim of the paper was to measure the limit strains for high strength steel (AHSS) sheet of HCT $490 X+Z 100$ by Nakajima test. HCT490X+Z100 is a hot dip galvanized $(5-12 \mu \mathrm{m})$ dual-phase steel. The structure consists of hard martensitic phase dispersed in the form of islands and ductile ferritic matrix. It is a low carbon steel with a $10-40 \%$ share of martensite. This combination allows a good combination of hardness, ductility and weldability. The HCT490X $+Z 100$ bake hardening steel can thus achieve higher strength in the finished part while retaining good forming performance. The gain in yield strength through the "bake hardening" $(\mathrm{BH})$ effect is generally greater than $30 \mathrm{MPa}$. Thanks to this $\mathrm{BH}$ effect, this steels offer advantages compared to conventional drawing quality steels in improved dent resistance in all finished parts in the case of low forming strains (hood, roof, doors and wings) and substantial weight reduction potential at equivalent dent resistance (the decrease in thickness is offset by increased yield strength resulting from the heat treatment process). [810]

Selected mechanical properties of dual-phase steel HCT490X are mentioned in Table 1. Chemical composition of HCT490X is shown in Table 2.

Table 1 Mechanical properties of HCT490X according to ČSN EN 10346 [8]

\begin{tabular}{|c|c|c|c|c|c|c|}
\hline \multirow{2}{*}{$\begin{array}{c}\text { Numerical } \\
\text { designation }\end{array}$} & $\begin{array}{c}\text { Proof } \\
\text { strength } \\
(\mathrm{MPa})\end{array}$ & $\begin{array}{c}\text { Tensile } \\
\text { Strength } \\
(\mathrm{MPa})\end{array}$ & $\begin{array}{c}\text { Elongation } \\
\text { after fracture } \\
(\mathbf{w t} \%)\end{array}$ & $\begin{array}{c}\text { Plastic } \\
\text { strain ratio } \\
(-)\end{array}$ & $\begin{array}{c}\text { Strain } \\
\text { hardening } \\
\text { exponent }(-)\end{array}$ & $\begin{array}{c}\text { Bake } \\
\text { hardening } \\
(\mathrm{MPa})\end{array}$ \\
\cline { 2 - 7 } & $R_{\mathrm{p} 0,2}$ & $R_{\mathrm{m}}$ & $A_{80 \mathrm{~mm}}$ & $r_{\mathrm{m} / 20}$ & $n_{10-20 / \mathrm{Ag}}$ & $\mathrm{BH}_{2}$ \\
\hline 1.0995 & $290-380$ & $\geq 490$ & $\geq 24$ & $(\approx 1.0)$ & $\geq 0.15$ & $\geq 30$ \\
\hline
\end{tabular}

Table 2 Chemical composition of HCT490X according to ČSN EN 10346 [8]

\begin{tabular}{|c|c|c|c|c|c|c|c|c|c|}
\hline $\begin{array}{c}\mathbf{C} \\
(\mathbf{w t} \%)\end{array}$ & $\begin{array}{c}\mathrm{Si} \\
(\mathbf{w t} \%)\end{array}$ & $\begin{array}{c}\mathbf{M n} \\
(\mathbf{w t} \%)\end{array}$ & $\begin{array}{c}\mathbf{P} \\
(\mathbf{w t} \%)\end{array}$ & $\begin{array}{c}\mathbf{S} \\
(\mathbf{w t} \%)\end{array}$ & $\begin{array}{c}\mathbf{A} \text { ) } \\
(\mathbf{w t} \%)\end{array}$ & $\begin{array}{c}\mathbf{N b}+\mathrm{Ti} \\
(\mathbf{w t} \%)\end{array}$ & $\begin{array}{c}\mathbf{C r}+\mathbf{M o} \\
(\mathbf{w t} \%)\end{array}$ & $\begin{array}{c}\mathbf{V} \\
(\mathbf{w t} \%)\end{array}$ & $\begin{array}{c}\mathrm{B} \\
(\mathbf{w t} \%)\end{array}$ \\
\hline$\leq 0.14$ & $\leq 0.75$ & $\leq 2.00$ & $\leq 0.080$ & $\leq 0.015$ & $0.015-1.0$ & $\leq 0.15$ & $\leq 1.00$ & $\leq 0.20$ & $\leq 0.005$ \\
\hline
\end{tabular}

The limit strains have been measured by tool set for Nakajima test (Figure 1).

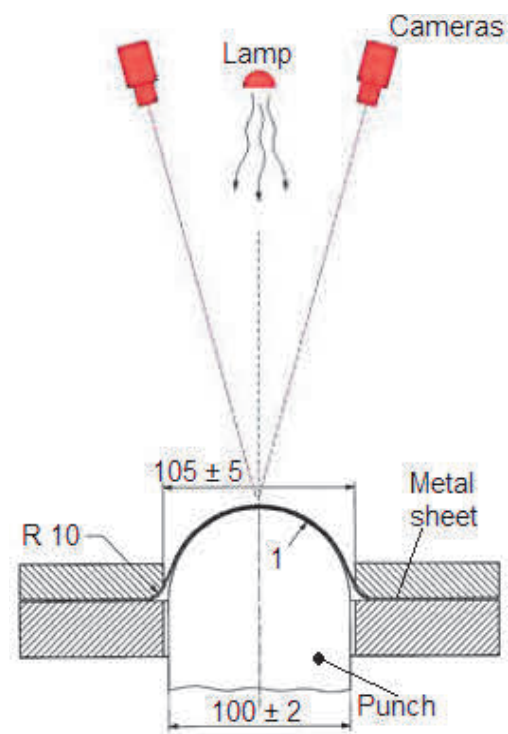

Figure 1 Scheme of the Nakajima test according to EN ISO 12004-2 1= lubrication layer

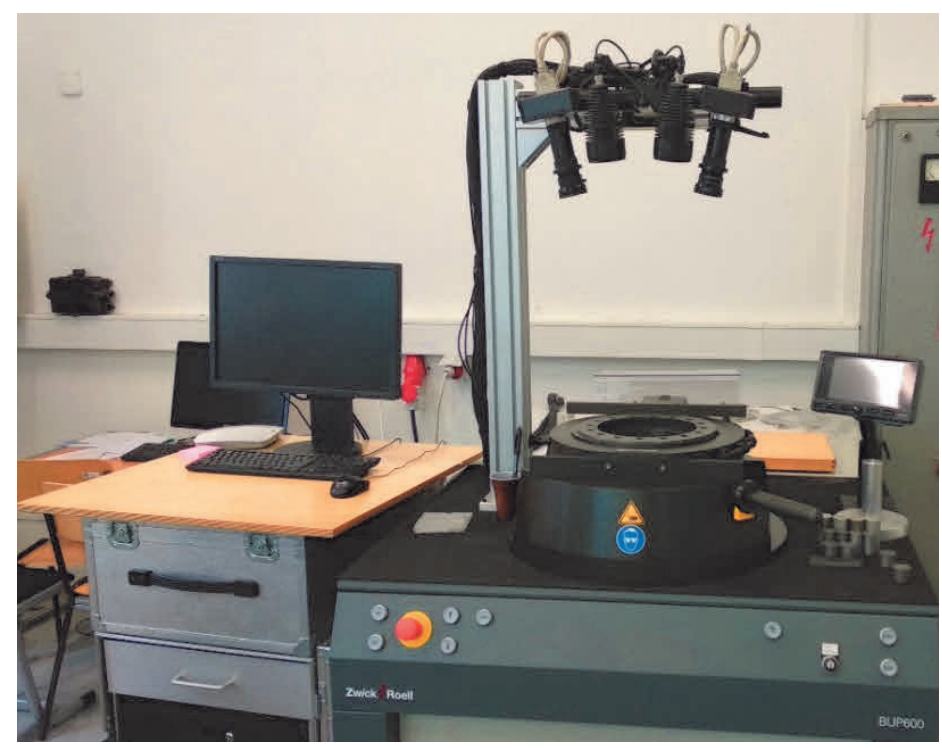

Figure 2 Universal sheet metal testing machine BUP600 with FLC tool and the ARAMIS system 
The stretching of the testing samples (flat sheet metal blanks) has been performed on universal testing machine BUP600 (Figure 2) with the maximum punch movement velocity of $17 \mathrm{~mm} / \mathrm{s}$ until the specimen fracture. The matter of the Nakajima test is stretching the specimens with different remaing blank width that provide several strain paths (different ratios between major strain and minor strain) from uni-axial to bi-axial deformation.

The test conditions are specified in the EN ISO 12004-2 including the specimens shape (Figure 3). The ISO 12004-2 specifies that at least five different geometries are to be tested with three repetitions of the each geometry. Waisted blanks with parallel shaft length of $35 \mathrm{~mm}$ and fillet radius of $25 \mathrm{~mm}$ have been prepared by laser cutting. Stochastic pattern (unrepeatable, isotropic and highly contrast) was applied by spraying white and black paint onto the test specimen surface. Necking and crack orientations for different values of specimen remaining blank width are shown in Figure 4. [1-3]

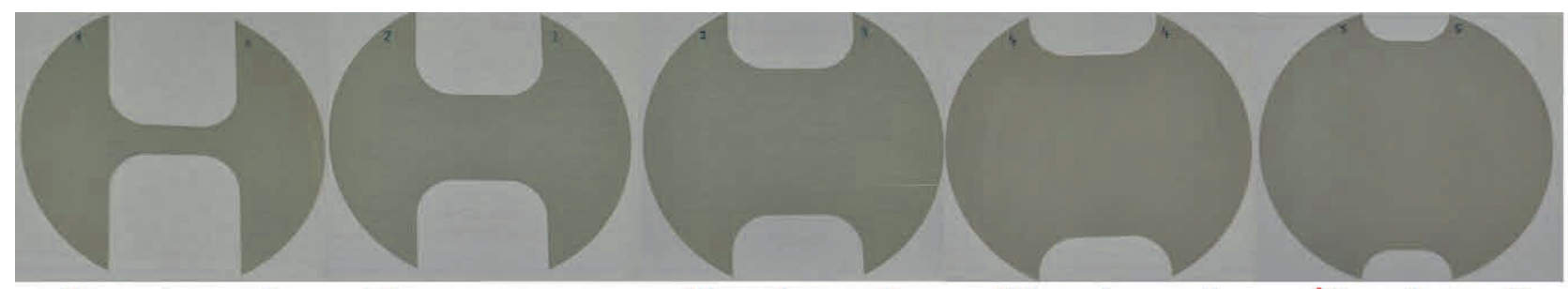
a)Specimen 1
b)Specimen 2
c)Specimen 3
d)Specimen 4
e)Specimen 5

Figure 3 Dog bone shaped specimens before Nakajima test with remaining blank width: a $=20 \mathrm{~mm}$, $\mathrm{b}=60 \mathrm{~mm}, \mathrm{c}=100 \mathrm{~mm}, \mathrm{~d}=125 \mathrm{~mm}, \mathrm{e}=150 \mathrm{~mm}$

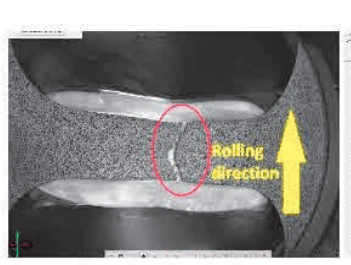

a)Specimen 1

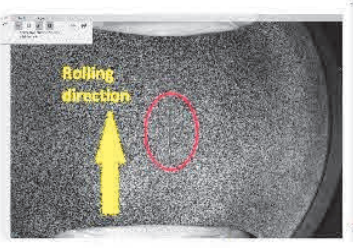

b)Specimen 2

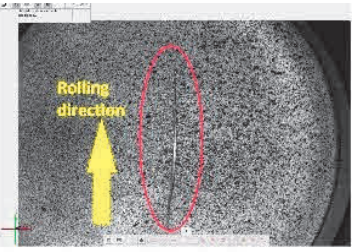

c)Specimen 3

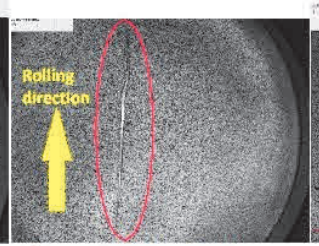

d)Specimen 4

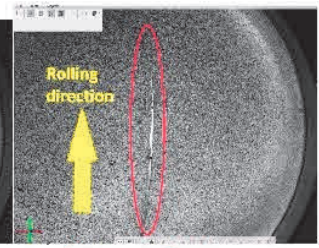

e)Specimen 5

Figure 4 Dog bone shaped specimens with stochastic pattern after Nakajima test, Blank geometry for Nakajima test with remaining blank width: $a=20 \mathrm{~mm}, b=60 \mathrm{~mm}, \mathrm{c}=100 \mathrm{~mm}, \mathrm{~d}=125 \mathrm{~mm}, \mathrm{e}=150 \mathrm{~mm}$

\section{THE SECTION BASE METHOD}

This calculation method requires a section based post-processing of the strain data sets that you gather with the ARAMIS system and it requires as well a minimum sampling rate of $10 \mathrm{~Hz}(10$ pictures per second for punch movement velocity $1.5 \mathrm{~mm} / \mathrm{s}$ ) to have enough strain data set samples to evaluate. The section line will post-process the major strain and minor strain value to calculate forming limit values then plotted in the forming limit curve. The three sections are to be placed with the distance of $2 \mathrm{~mm}$ to each other and they have to be defined in the stage before the crack appears on the specimen (Figures 7, 8). After that, the data is plotted in a graph (Figure 9). This procedure at least 15 repeated for each of the five geometries of specimens. After ending this procedure the FLD has five point for plotting final forming limit curve. [1,2]

Strain measurement was performed in the central test piece zone, close to the crack of the material.

Positioning of cross sections on deformation map and also calculated values of major and minor strains (Figure 9) was achieved according to [1].

The crack position has to be determined by a best fit of a parabola according to (1):

$$
f(x)=a \cdot x^{2}+b \cdot x+c
$$




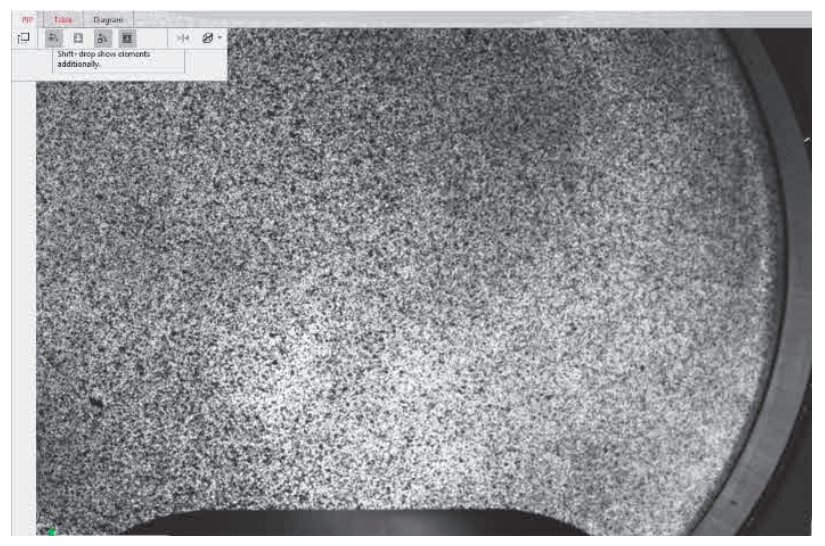

Figure 5 Original reference pattern

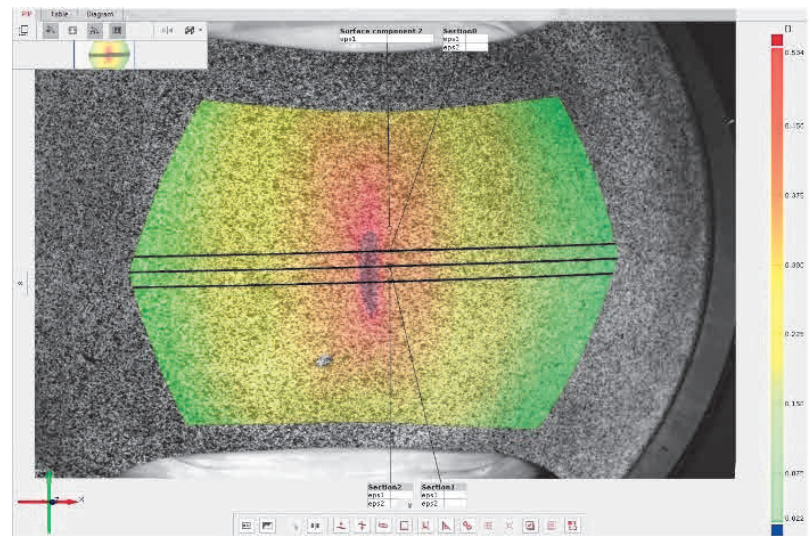

Figure 7 The section based method with three section line

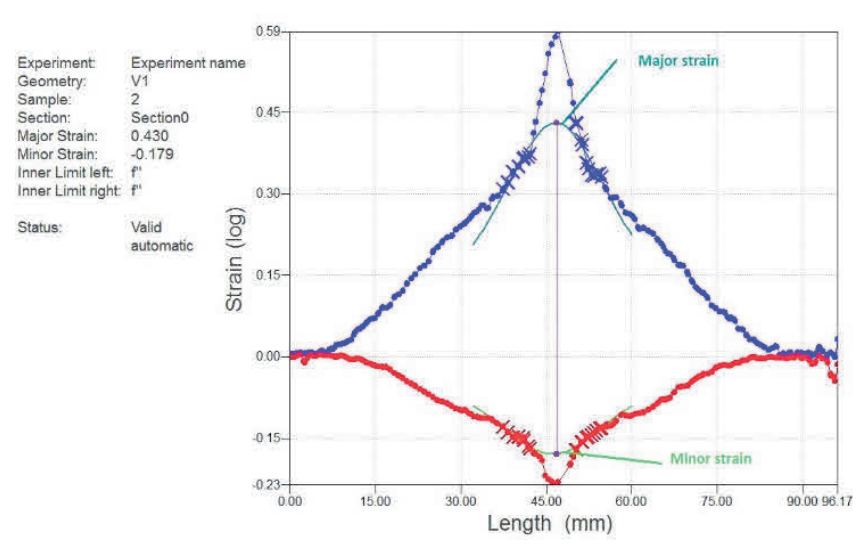

Figure 9 Determining of limit strain by interpolation method

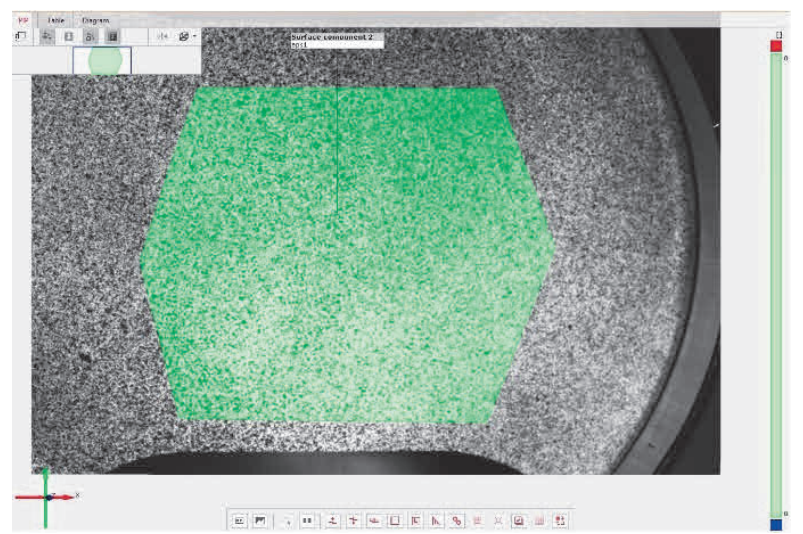

Figure 6 Verification pattern quality

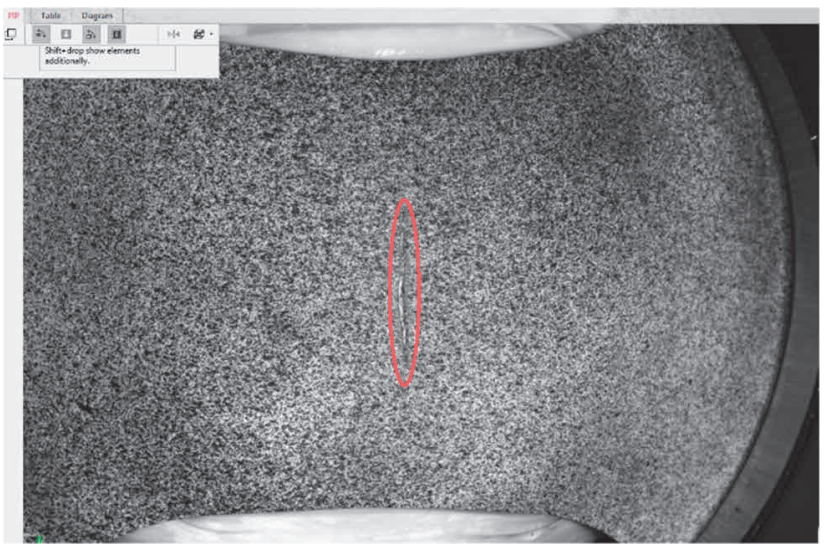

Figure 8 Specimen after ending Nakajima test with fracture occurred

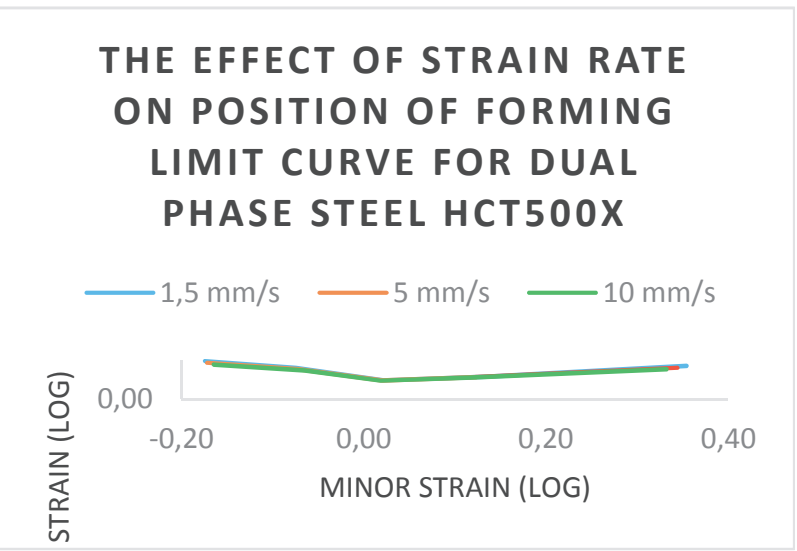

Figure 10 The forming limit curves constructed by section based method

From each test specimen shape was carried out several tests. The subsequent statistical evaluation was used only from valid samples, i.e. samples, where the crack occurred in distance of $15 \%$ of the diameter of the punch from the center of the dome. PTFE tape, PE foil and lanolin were used as a lubricant layer in this way to avoid cracking exceeding $15 \%$ of the punch diameter from apex of the dome. [1] The final forming limit curves for different punch movement velocity is illustrated in Figure 10. 


\section{CONCLUSION}

This article deals with the problem of limit strain curves. The method of evaluating forming limit curve is described in the introduction and the chapter the base method of the article. The actual experiment was performed on the BUP 600 where the punch movement velocity of the tool was changed during the experiment. The Nakajima test method was used for the experiment and results was evaluated using ARAMIS software. The experiment was provided on material HCT490X+Z100.

The forming limit curve for the selected material has not yet been reported in the literature. Therefore, in our paper, we introduced the FLC curve for the selected material. Our experiment was extended by the dependence of punch movement velocity to position of FLC for chosen material. The maximum punch movement velocity was limited by the amount of light so for higher punch movement velocity is necessary higher scanning frequency and also more light for tracking.

\section{ACKNOWLEDGEMENTS}

The research was financed by SGS19/163/OHK2/3T/12.

Research, optimization and innovation of production processes.

\section{REFERENCES}

[1] EN ISO 12004-2: Metallic materials. Sheet and strip. Determination of forming-limit curves. 2008

[2] KLEIN, M. ARAMIS: Determination of forming limit curves. GOM Webinar. 2014.

[3] SLOTA, J., JURČIŠIN, M., SPIŠÁK, E., ŠISER, M. Experimental FLC determination of high strength steel sheet metal. Acta Metallurgica Slovaca. 2015. vol. 21, pp. 269-277. Available from: DOI: 21. 269.

10.12776/ams.v21i4.639.

[4] HOTZ, W., W., TIMM, J. Experimental detection of forming limit curves (FLC). In NUMISHEET INTERNATIONAL CONFERENCE 2008: 7th International Conference and Workshop on Numerical Simulation of 3D Sheet Metal Forming Processes. Interlaken: Switzerland, pp. 271-278.

[5] VOLK, W., HORA, P. New algorithm for a robust user-independent evaluation of beginning instability for the experimental FLC determination. International Journal of Material Forming. 2011. vol. 4, pp. 339-346. Available from: DOI: 10.1007/s12289-010-1012-9.

[6] EBERLE, B., VOLK, W., HORA, P. Automatic approach in the evaluation of the experimental FLC with a full 2D approach based on a time depending method, In NUMISHEET - INTERNATIONAL CONFERENCE 2008: 7th International Conference and Workshop on Numerical Simulation of 3D Sheet Metal Forming Processes. Interlaken: Switzerland, pp. 279-284.

[7] KEELER, S. The Science of Forming: FORMING-LIMIT DIAGRAMS. Metalformingmagazine [online]. Date: 201607-01 [update]. [viewed 2019-04-30]. Avaible from:

https://www.metalformingmagazine.com/magazine/article/Default.asp?/Forming-Limit Diagrams: Then and Now

[8] ČSN EN 10346: Continuously hot-dip coated steel flat products for cold forming - Technical delivery conditions. 2016

[9] KUZIAK, R., KAWALLA, R., WAENGLER, S. Advanced high strength steels for automotive industry. In: Archives of Civil and Mechanical Engineering [online]. 2008, vol. 8, no. 2, pp. 103-117. Available from: DOI: 10.1016/S1644-9665(12)60197-6.

[10] KONG, Z., ZHANG, J., LI, H., KONG, N. Deep drawing and bulging forming limit of dual-phase steel under different mechanical properties. In International Journal of Advanced Manufacturing Technology [online]. 2018, vol. 97, no. 5-8, pp. 2111-2124. Available from: DOI: 10.1007/s00170-018-1980-3. 